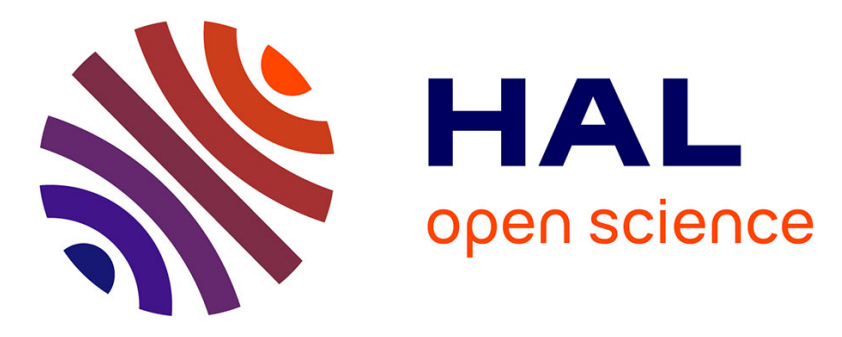

\title{
Experimental study of PLA thermal behavior during fused filament fabrication
}

\author{
Hamid Reza Vanaei, Mohammadali Shirinbayan, Sidonie Fernandes Costa, \\ Fernando Moura Duarte, José António Covas, Michael Deligant, Sofiane \\ Khelladi, Abbas Tcharkhtchi
}

\section{To cite this version:}

Hamid Reza Vanaei, Mohammadali Shirinbayan, Sidonie Fernandes Costa, Fernando Moura Duarte, José António Covas, et al.. Experimental study of PLA thermal behavior during fused filament fabrication. Journal of Applied Polymer Science, 2021, 138 (4), pp.49747. 10.1002/app.49747 . hal03164728

\section{HAL Id: hal-03164728 \\ https://hal.science/hal-03164728}

Submitted on 10 Mar 2021

HAL is a multi-disciplinary open access archive for the deposit and dissemination of scientific research documents, whether they are published or not. The documents may come from teaching and research institutions in France or abroad, or from public or private research centers.
L'archive ouverte pluridisciplinaire $\mathbf{H A L}$, est destinée au dépôt et à la diffusion de documents scientifiques de niveau recherche, publiés ou non, émanant des établissements d'enseignement et de recherche français ou étrangers, des laboratoires publics ou privés. 


\title{
Experimental study of PLA thermal behavior during fused filament fabrication
}

\author{
Hamid Reza Vanaei ${ }^{1,2}$ (1) | Mohammadali Shirinbayan ${ }^{2}$ | \\ Sidonie Fernandes Costa ${ }^{3}$ | Fernando Moura Duarte ${ }^{4}$ | José António Covas ${ }^{4}$ | \\ Michael Deligant $^{1}$ | Sofiane Khelladi ${ }^{1}$ | Abbas Tcharkhtchi ${ }^{2}$
}

\author{
${ }^{1}$ Arts et Metiers Institute of Technology, \\ CNAM, LIFSE, HESAM University, Paris, \\ France \\ ${ }^{2}$ Arts et Metiers Institute of Technology, \\ CNRS, CNAM, PIMM, HESAM \\ University, Paris, France \\ ${ }^{3}$ School of Technology and Management \\ of Porto Polytechnic Institute, CIICESI - \\ Center for Research and Innovation in \\ Business Sciences and Information \\ Systems, Felgueiras, Portugal \\ ${ }^{4}$ IPC - Institute for Polymers and \\ Composites, Department of Polymer \\ Engineering, University of Minho, \\ Guimarães, Portugal \\ Correspondence \\ Hamid Reza Vanaei, Arts et Metiers \\ Institute of Technology, CNAM, LIFSE, \\ HESAM University, F-75013 Paris, \\ France. \\ Email: hamidreza.vanaei@ensam.eu
}

\begin{abstract}
Fused filament fabrication (FFF) is an additive manufacturing technique that is used to produce prototypes and a gradually more important processing route to obtain final products. Due to the layer-by-layer deposition mechanism involved, bonding between adjacent layers is controlled by the thermal energy of the material being printed, which strongly depends on the temperature development of the filaments during the deposition sequence. This study reports experimental measurements of filament temperature during deposition. These temperature profiles were compared to the predictions made by a previously developed model. The two sets of data showed good agreement, particularly concerning the occurrence of reheating peaks when new filaments are deposited onto previously deposited ones. The developed experimental technique is shown to demonstrate its sensitivity to changing operating conditions, namely platform temperature and deposition velocity. The data generated can be valuable to predict more accurately the bond quality achieved in FFF parts.
\end{abstract}

\section{K E Y W O R D S}

manufacturing, thermal properties, thermoplastics

\section{1 | INTRODUCTION}

Additive manufacturing (AM) denotes a group of innovative technologies that enable the rapid fabrication of three dimensional (3D) physical objects directly from computer-aided design (CAD) data without the use of tooling. Parts with complex geometry that are difficult to produce using traditional manufacturing processes can be obtained by AM. ${ }^{1,2}$ A large array of AM techniques is currently used to process thermoplastic polymers, polymer composites, metals, and ceramics. ${ }^{3-6}$

Fused filament fabrication (FFF) is extensively used to produce prototypes for applications in, for example, the aerospace, medical, and automotive industries. ${ }^{7,8}$ In this process, a thermoplastic polymer is fed into a liquefier that extrudes a filament while moving in successive $X-Y$ planes along the $Z$ direction, to fabricate a 3D part layer-by-layer. ${ }^{9}$ Consequently, as the deposition progresses, the hot filament is deposited onto filaments that were previously deposited and that are now in the process of cooling. This causes their reheating, defining a time during which the interfaces of contacting filaments are above the glass transition temperature $\left(T_{\mathrm{g}}\right)$ in the case of amorphous materials, or of the crystallization temperature $\left(T_{\mathrm{c}}\right)$ for semicrystalline materials, which is necessary for proper bonding to take place. ${ }^{10,11}$ Therefore, each filament should be sufficiently hot during deposition, but not too hot, to avert deformation due to gravity and to the weight of the filaments deposited in subsequent layers. 
Given the above, the evolution of the temperature profile of the filaments during deposition is a key parameter affecting the bonding quality. ${ }^{12}$ Both experimental and theoretical approaches have been proposed to obtain data on the temperature profile of a printed structure. ${ }^{13}$ Generally, temperature measurements are limited to a single location. Also, the deposition may be interrupted to fix a thermocouple to the part being fabricated. ${ }^{14}$ To circumvent this limitation, infrared (IR) thermography has been used. This approach yields the surface temperature, but it cannot read the temperature at the interface of adjacent layers, both due to the camera measurement accuracy and the small filament dimensions. ${ }^{15}$ Ferraris et al. ${ }^{16}$ used IR thermography to measure the temperature profile of a vertical wall, but the comparison with theoretical predictions showed poor agreement. Kousiatza et al. ${ }^{17}$ applied local measurement of the temperature profile in a specific case on acrylonitrile butadiene styrene (ABS) using $K$-type thermocouples $(\mathrm{d}=250 \mu \mathrm{m})$ by pausing the process manually to add them. Although they have concluded that there is a good agreement between experimental and theoretical results, the sudden drop of temperature at the head tip of the extruder clearly shows that there is still a gap between the monitored and numerically derived temperature peak values.

Theoretical efforts to model the temperature profile have focused on 1D or 2D approaches. Sun et al. ${ }^{18}$ and Zhang et al. ${ }^{19}$ investigated both numerically and experimentally the effect of numerous parameters that exist in the nature of the process. Yardimci and Güçeri ${ }^{20}$ developed a 1D numerical model to predict the cooling/bonding in fused deposition of ceramics, considering exclusively convection with the environment. Bellehumeur et al. ${ }^{21}$ also developed a 1D model with the same assumption of taking into account the temperature profile along the length of the deposited filament. More recently, Costa et al. ${ }^{22}$ developed a computer code that takes into account the heat transfer between adjacent filaments during deposition and predicts temperature and adhesion quality for most 3D-printed parts. The model was shown to be in good agreement with experimental data. ${ }^{23}$

Despite the above developments, there is still a lack of practical knowledge on the temperature development of filaments during the deposition stage in FFF. To address this limitation, A. Tcharkhtchi et al. ${ }^{24}$ added thermocouples to the build simultaneously with the fabrication without damaging or pausing the process. However, a drop of approximately $50^{\circ} \mathrm{C}$ was observed on the experimental data. This work presents an improved measurement setup enabling to record the temperature evolution in various locations of the part during deposition, including the interface between two adjacent filaments. The data collected is compared with the predictions provided by the model of Costa et $\mathrm{al}^{22}$ that have been already developed.

The paper is organized as follows. The experimental procedure is presented in detail and the used heat transfer model is introduced. The temperature evolutions of a single PLA filament and a vertical wall are measured experimentally and the data are compared with the theoretical predictions for validation purposes. Finally, the usefulness of the new experimental method is illustrated by studying the influence of the platform temperature and deposition velocity on the heat transfer during cooling.

\section{2 | EXPERIMENTS}

\section{1 | Materials}

A commercial PLA filament with a diameter of $1.75 \mathrm{~mm}$ $( \pm 0.01 \mathrm{~mm})$ and a density of $\rho=1.24 \mathrm{~g} / \mathrm{cm}^{3}$ have been used. Differential scanning calorimetry (DSC Q10 from TA Company) determined the crystallization and the melting temperature of the material before and after printing. The test was performed by subjecting a $6.8 \mathrm{mg}$ sample from room temperature to $210^{\circ} \mathrm{C}$ at a heating rate of $5^{\circ} \mathrm{C} / \mathrm{min}$ under nitrogen atmosphere. To measure the main transition temperatures, dynamic mechanical analysis tests were performed (DMA Q800 from TA Company) under tensile mode from 40 to $100^{\circ} \mathrm{C}$ at a temperature rate of $2^{\circ} \mathrm{C} / \mathrm{min}$ and a frequency of $1 \mathrm{~Hz}$. The rectangular sample with a dimension of $25 \times 10 \mathrm{~mm}^{2}$ was used. For both DSC and DMA characterization, 'TA instrument' software was applied in measurement of the $T_{\mathrm{g}}$, the $T_{\mathrm{c}}$, the melting temperature $\left(T_{\mathrm{m}}\right)$ and the enthalpy at these temperatures $(\Delta \mathrm{H})$ of both materials.

\section{2 | 3D printing}

The printed parts were manufactured by a desktop 3D printer fitted with a single nozzle $(\mathrm{d}=0.4 \mathrm{~mm})$ printing head and a temperature-controlled atmosphere (build platform). The solid model file corresponding to the part illustrated in Figure 1 was designed using the FreeCad software and then exported as stereolithography (STL) format to be loaded into the FlashPrint software, which generates the printing path.

The test case was built considering the values for the processing variables (Table 1) that are commonly used in the desktop 3D printer to ensure a good quality part in terms of bonding between filaments and mechanical strength. ${ }^{21,25-28}$ 


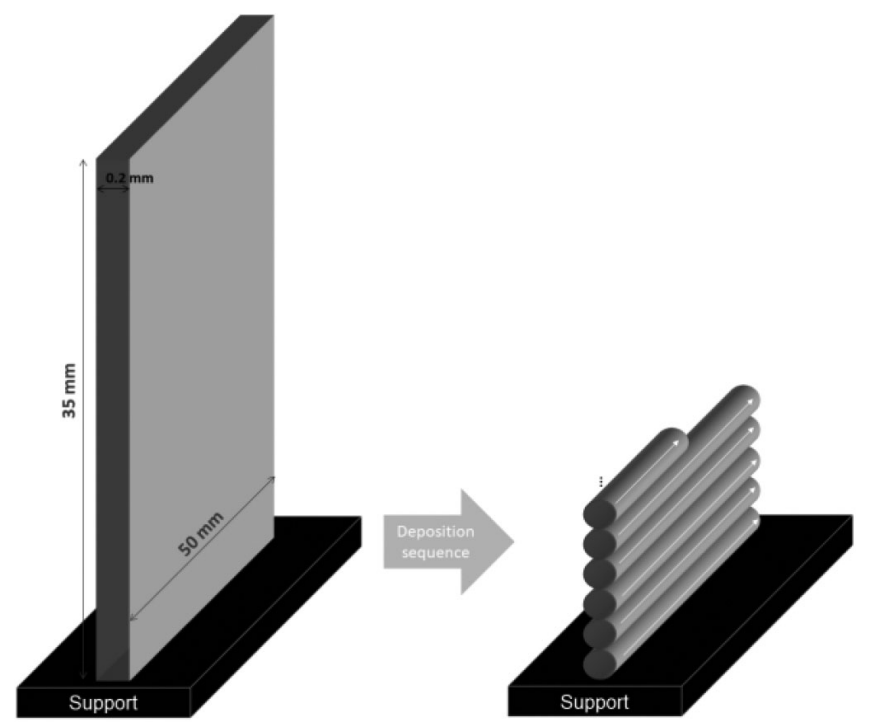

FI G URE 1 Schematic of the test case representing the deposition mechanism of each layer

TAB L E 1 Process parameters used for printing

\begin{tabular}{lc|} 
Parameter & Value \\
\hline Liquefier temperature $\left({ }^{\circ} \mathrm{C}\right)$ & 210 \\
\hline Platform temperature $\left({ }^{\circ} \mathrm{C}\right)$ & 60 \\
\hline Printing speed $(\mathrm{mm} / \mathrm{s})$ & 20 \\
Layer height $(\mathrm{mm})$ & 0.2 \\
\hline Infill $(\%)$ & 100 \\
Filament cross-section & Circular \\
\hline
\end{tabular}

\subsection{In situ temperature measurements}

In situ temperature measurement methods should be sufficiently precise and quick to track filament cooling and the reheating peaks arising from contact between freshly and previously deposited filaments. In addition, it should be possible to apply the sensor locally without the need to pause the process. A very small $K$-type thermocouple $(\mathrm{d}=80 \mu \mathrm{m})$, capable of measuring temperatures between $-75^{\circ} \mathrm{C}$ and $250^{\circ} \mathrm{C}$, was used. By taking advantage of this size, it is possible to squeeze the device between two adjacent filaments. The thermocouple is connected to a Datapaq $^{\circledast}$ Tracker Telemetry system (previously employed for the in situ temperature measurement in rotational molding process ${ }^{29}$ ) for temperature recording and connection to a polycarbonate (PC). As shown in Figure 2 (setup of the work), when the print was started by fabrication of the support (by opening the door) thermocouple placed at the location of $5 \mathrm{~mm}$ from the starting point of the deposition and then the door closed in order to have a stabilized temperature of the environment.

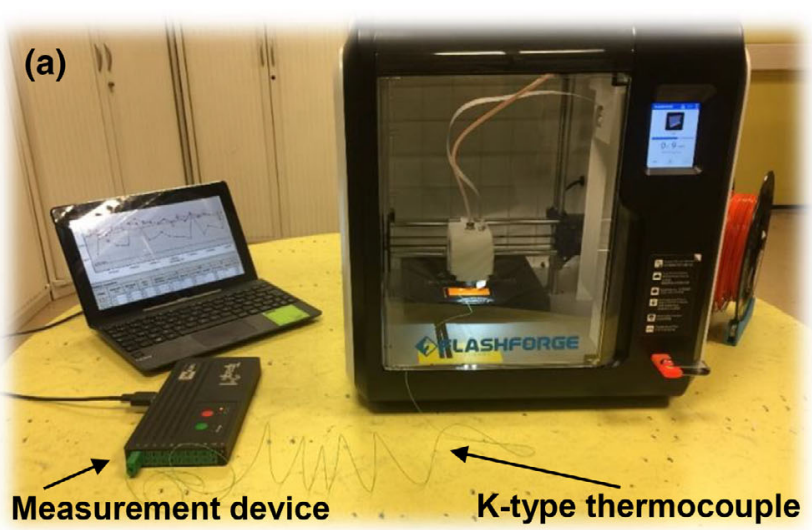

(b)

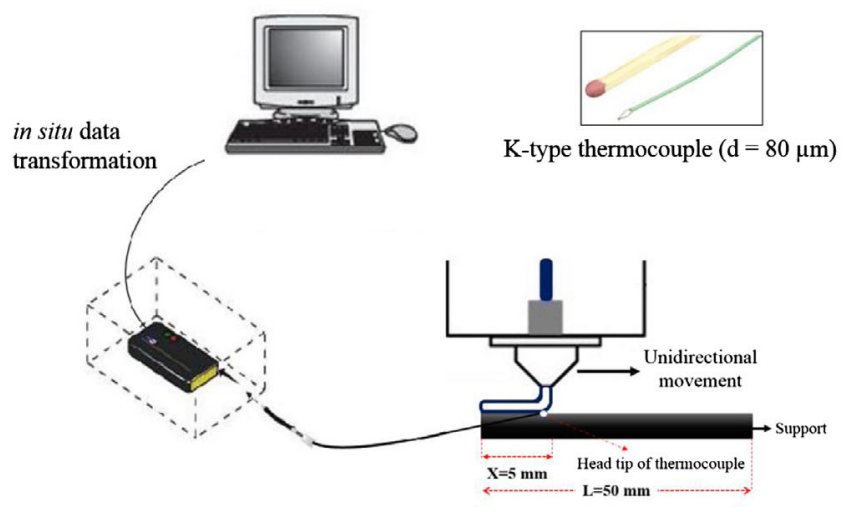

F I G URE 2 (a) Setup and b) schematic used for the in situ measurement of temperature during the deposition stage in FFF [Color figure can be viewed at wileyonlinelibrary.com]

\section{3 | MODELLING OF FILAMENT COOLING DURING DEPOSITION}

Heat transfer during deposition is complex, with contributions from radiation, convection, and conduction. However, it has been demonstrated that (a) the heat losses by convection with the environment (b) the thermal contacts with the support and with adjacent filaments are the main contributors to the filament temperature evolution. ${ }^{22}$ A computer code that has been already developed, was applied assuming the gradual deposition of small axial filament segments, an analytical solution for the energy equation ${ }^{30}$ whilst updating the local thermal conditions, and a healing criterion proposed by Yang and Pitchumani. ${ }^{31}$ This gave rise to a useful tool that allows us to predict the temperature evolution and the degree of bonding between filaments for 3D parts including the usage of two distinct materials (e.g., the material of the part plus support material).

Figure 3 shows the evolution of the temperature of the filaments at specific instants upon building the first ten layers of a vertical wall. As in the experiments 

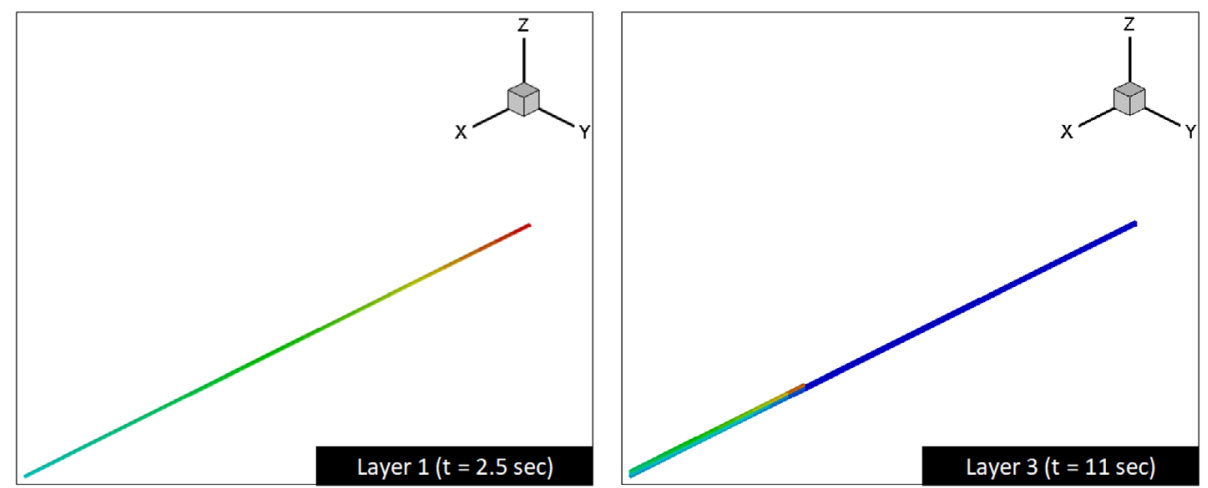

FIG U RE 3 Temperatures of the ten first layers of the vertical wall at some instants of the deposition process [Color figure can be viewed at wileyonlinelibrary.com]
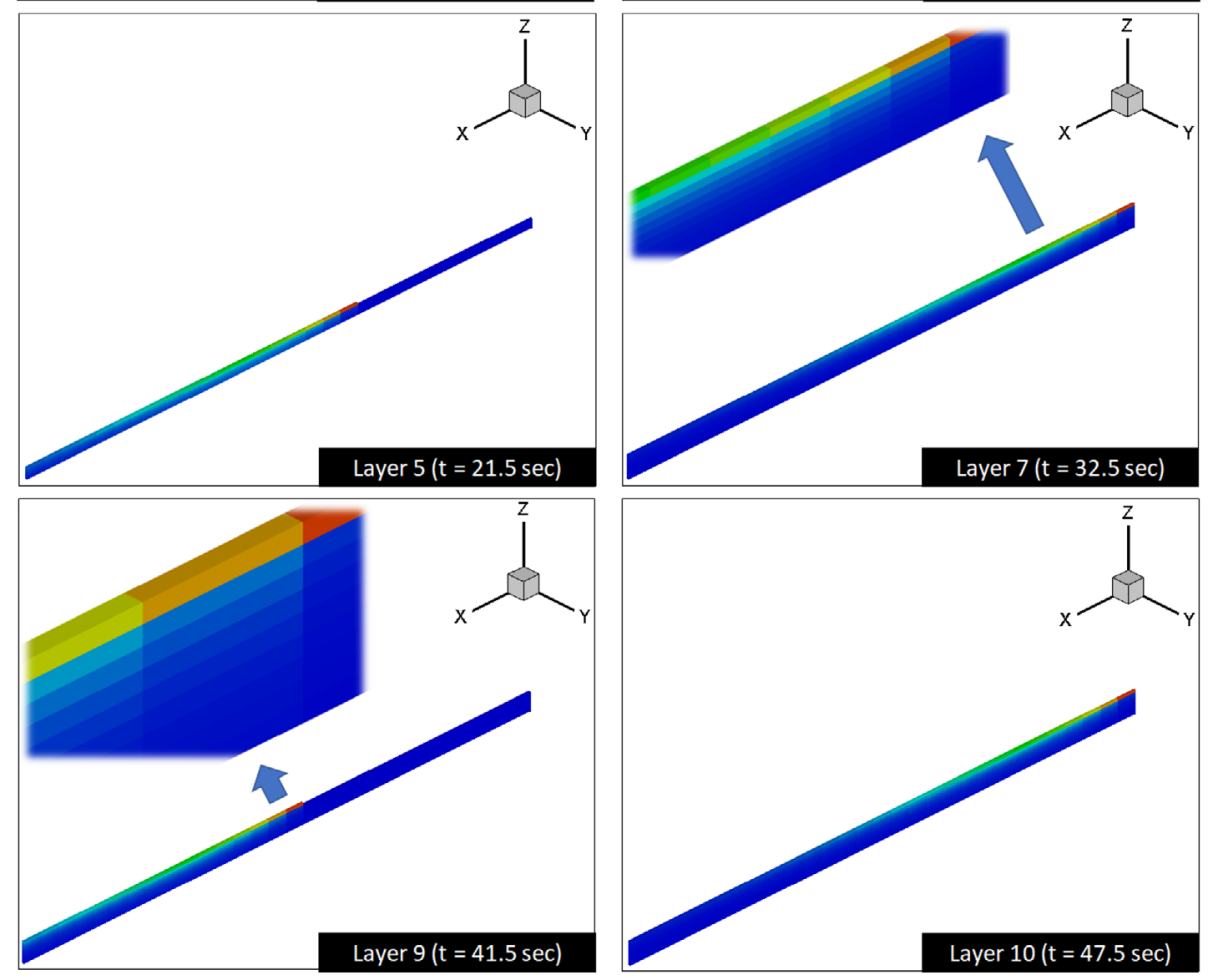

reported in this work, the liquefier deposits one filament, then stops and returns to the initial point to deposit the next filament. Under these printing conditions, when a new filament is deposited, the previous one has already significantly cooled down. Nevertheless, the deposition of a new hot filament prompts the reheating of filaments of the previous layers (as seen at 32.5 and $41.5 \mathrm{~s}$ ), thus demonstrating the importance of considering the thermal contacts in the calculations.

\section{4 | RESULTS AND DISCUSSION}

\section{1 | Polymer characterization}

Figure 4(a) shows the DSC traces for the PLA filament and the printed part. The $T_{\mathrm{g}}$, the $T_{\mathrm{c}}$, the $T_{\mathrm{m}}$, and the enthalpy at these temperatures $(\Delta \mathrm{H})$ of both materials are measured and summarized in Table 2 . The temperature range between the crystallization and melting temperatures (102 to $148^{\circ} \mathrm{C}$ ) is paramount for $\mathrm{FFF}$, as it determines the extent of diffusion for bonding purposes. Moreover, from DMA result (Figure 4(b)) the $T_{\mathrm{g}}$ was detected to be around $57^{\circ} \mathrm{C}$.

\section{2 | Validation of the measurement methodology}

For validation purposes, the temperature evolution of PLA during the deposition of a single filament and of a vertical wall as measured using the applied methodology was compared with the predictions of the thermal model. 
F I G URE 4 (a) DSC and (b) DMA traces for PLA filaments. DSC, differential scanning calorimetry; DSC, differential scanning calorimetry [Color figure can be viewed at wileyonlinelibrary.com] (a)

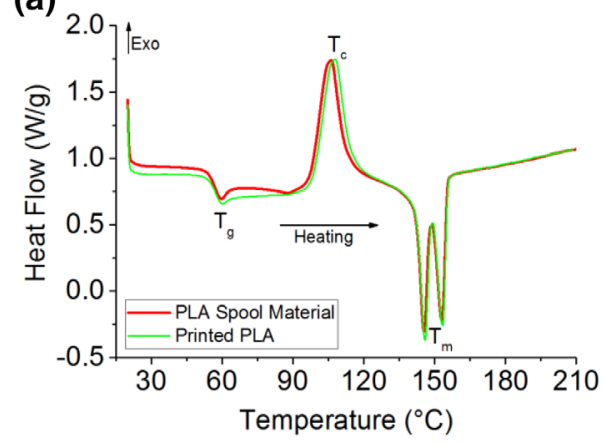

(b)

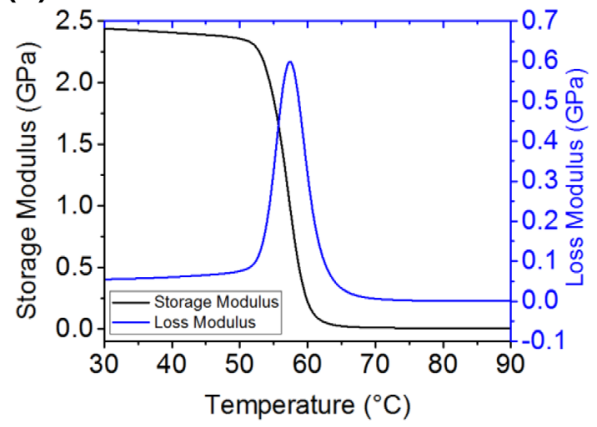

T A B LE 2 Thermal properties of PLA (before and after printing as obtained from DSC and DMA)

\begin{tabular}{lcc} 
Properties & PLA spool material & Printed PLA \\
\hline$T_{\mathrm{g}}\left({ }^{\circ} \mathrm{C}\right)$ & 56.6 & 54.6 \\
$T_{\mathrm{c}}\left({ }^{\circ} \mathrm{C}\right)$ & 102 & 107 \\
$\Delta \mathrm{H}$ at $T_{\mathrm{c}}(\mathrm{j} / \mathrm{gr})$ & 19.23 & 22.36 \\
$T_{\mathrm{m}}\left({ }^{\circ} \mathrm{C}\right)$ & 148 & 149 \\
$\Delta \mathrm{H}$ at $T_{\mathrm{m}}(\mathrm{j} / \mathrm{gr})$ & 3.8 & 8.2 \\
\hline
\end{tabular}

Abbreviations: DMA, dynamic mechanical analysis; DSC, differential scanning calorimetry.

\subsection{1 | Deposition of a single filament}

The temperature evolution during the deposition of a single filament is presented in Figure 5 for the first deposited filament. Both experimental measurements and theoretical curves for two values of the heat transfer coefficient are shown. Practice revealed that opening/closing the door of the environmental chamber to add/remove thermocouples would slightly disturb the platform temperature. This is why an interval in the range $50-60^{\circ} \mathrm{C}$ (approximated using thermocouples to see the temperature variation of the platform) and not the value of $60^{\circ} \mathrm{C}$ (see Table 1) is shown in the mentioned figure (Figure 5). The value of $70 \mathrm{~W} / \mathrm{m}^{2}{ }^{\circ} \mathrm{C}$ for the heat transfer coefficient $\left(h_{\text {conv }}\right)$ is commonly used (e.g. ${ }^{32}$ ). A value of $88 \mathrm{~W} / \mathrm{m}^{2 \circ} \mathrm{C}$ is obtained when using the Churchill correlation for the cooling down of a cylinder by natural convection ${ }^{33}$ :

$$
h_{\mathrm{conv}}=\frac{\mathrm{Nu}_{\mathrm{d}} \cdot k}{d} .
$$

where $d$ is the diameter $(\mathrm{m}), k$ is the thermal conductivity $\left(\mathrm{W} / \mathrm{m}{ }^{\circ} \mathrm{C}\right)$ and $N u_{\mathrm{d}}$ is the Nusselt number defined by:

$$
\mathrm{Nu}_{\mathrm{d}}=\left\{0.60+\frac{0.387 \mathrm{Ra}_{\mathrm{d}}^{1 / 6}}{\left[1+\left(\frac{0.559}{\mathrm{Pr}}\right)^{9 / 16}\right]^{8 / 27}}\right\}^{2} .
$$

where the Rayleigh $\mathrm{Ra}_{\mathrm{d}}$ number and $\mathrm{P}_{\mathrm{r}}$ are expressed as:

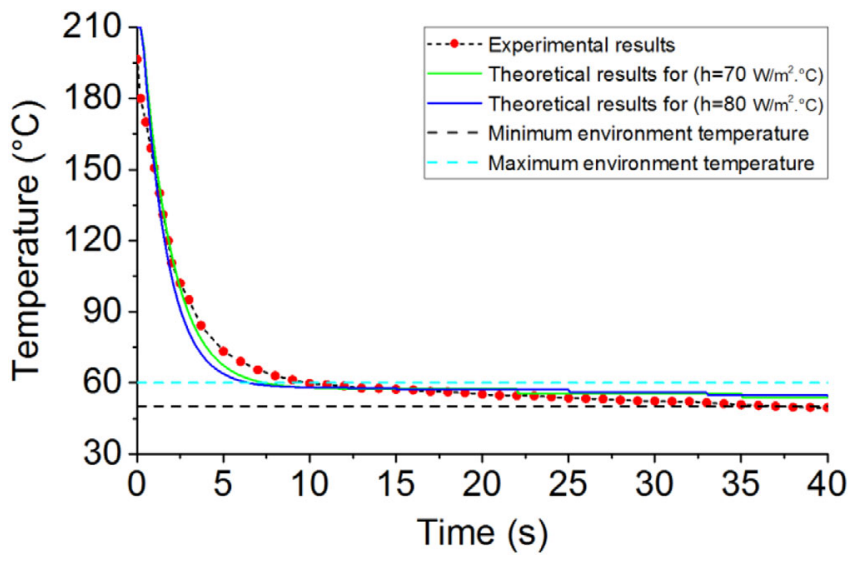

F I G U RE 5 Experimental $\left( \pm 2^{\circ} \mathrm{C}\right)$ and theoretical temperature evolution during the deposition of a single filament (at $x=5 \mathrm{~mm}$ ) [Color figure can be viewed at wileyonlinelibrary.com]

$$
\left\{\begin{array}{c}
\mathrm{Ra}_{\mathrm{d}}=\mathrm{Gr}_{\mathrm{d}} \mathrm{Pr} \\
\operatorname{Pr}=\frac{\nu_{\mathrm{k}}}{\alpha}
\end{array} .\right.
$$

In the above expressions, $v_{\mathrm{k}}$ is the kinematic viscosity $\left(\mathrm{m}^{2} / \mathrm{s}\right), \alpha$ is the thermal diffusivity $\left(\mathrm{m}^{2} / \mathrm{s}\right)$, and $\mathrm{Gr}_{\mathrm{d}}$ is the Grashof number:

$$
\mathrm{Gr}_{\mathrm{d}}=\frac{\mathrm{g} \beta\left(T_{\mathrm{s}}-T_{\mathrm{E}}\right) d^{3}}{v_{\mathrm{k}}^{2}}
$$

Here $g$ is the gravity acceleration $\left(9.8 \mathrm{~m} / \mathrm{s}^{2}\right), \beta$ is the volumetric thermal expansion coefficient, $T_{s}$ is the cylinder temperature $\left({ }^{\circ} \mathrm{C}\right)$ and $T_{\mathrm{E}}$ is the environment temperature $\left({ }^{\circ} \mathrm{C}\right)$.

Figure 5 shows a good agreement between the theoretical and the experimental values. The difference between the two sets of data occurs mostly between 3 and $8 \mathrm{~s}$, when the predicted cooling rate is higher than the one measured. This is probably due to the fact that the theoretical model does not consider the change in state and crystalline growth, and thus forecasts faster cooling. 


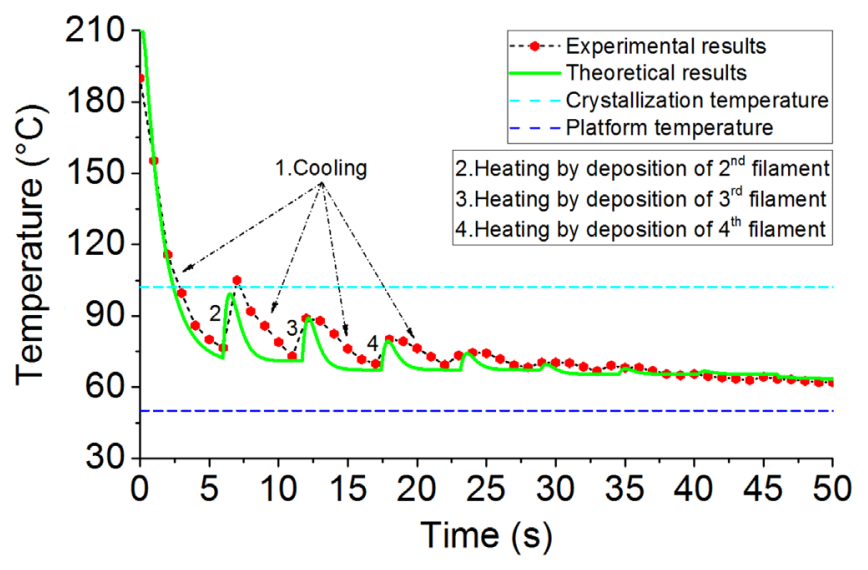

F I G URE 6 Experimental $\left( \pm 2^{\circ} \mathrm{C}\right)$ and theoretical temperature evolution of the first filament (at $x=5 \mathrm{~mm}$ ) during the deposition of a vertical wall consisting of single filaments deposited on top of each other. The numbers identify regions of the data: 1- cooling of the first filament, 2-4 reheating of the filament due to the deposition of filaments 2-4 [Color figure can be viewed at wileyonlinelibrary.com]

\subsection{2 | Deposition of a vertical wall}

Figure 6 depicts the evolution of the temperature of the first filament (at a location distant $5 \mathrm{~mm}$ from the edge) during the building of a vertical wall consisting of single filaments deposited on top of each other. It is clear that cooling of this first filament is significantly affected by the successive deposition of younger filaments, which may cause important reheating. The numbers identify regions of the data (1: cooling of the first filament; $2-4$ : reheating of the filament due to the deposition of filaments 2 to 4 ). The crystallization and platform temperatures are also identified.

For computational purposes, it is important to define the thermal contact conductance $(h)$ between adjacent filaments. This is difficult, as it depends on pressure, surface roughness, and other conditions that are difficult to quantify. ${ }^{34}$ Apparently, there are no theoretical or empirical correlations providing an exact value for $h$. Using a value of $\mathrm{h}=800 \mathrm{~W} / \mathrm{m}^{2}{ }^{\circ} \mathrm{C}$, the magnitude of the experimental and theoretical reheating peaks became virtually coincident.

Regardless of this approximation, the onset, relative magnitude, and breadth of the various temperature peaks are similarly captured by the two approaches. As expected, the peaks become gradually smaller with time, as the new filament being deposited is separated from the first filament by more filaments. As before, the predictions seem to overestimate the cooling rate, as no phase change and crystallization were built in the model. On the other hand, a delay in receiving the experimental data can exist and contribute to the differences.

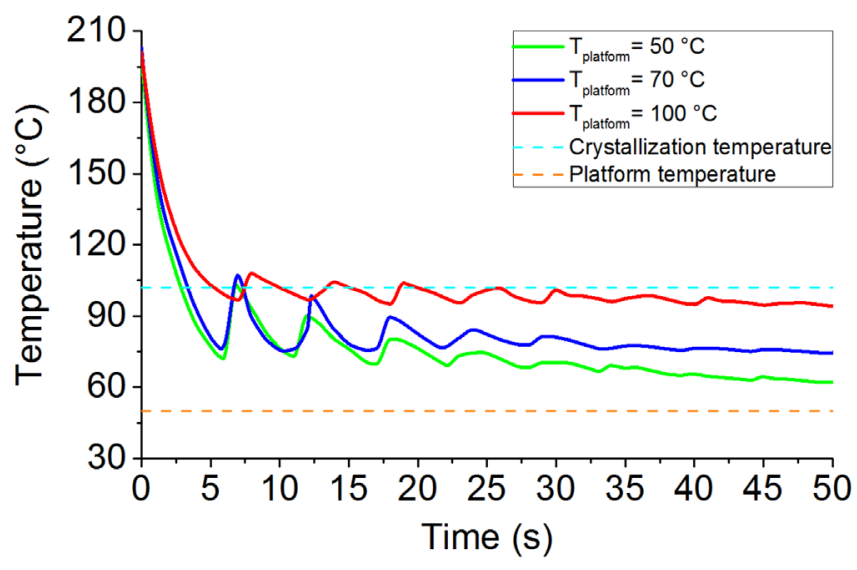

FIGURE 7 Temperature profile $\left( \pm 2^{\circ} \mathrm{C}\right)$ of vertical wall at $x=5 \mathrm{~mm}$ from the start of deposition at different platform temperatures [Color figure can be viewed at wileyonlinelibrary.com]

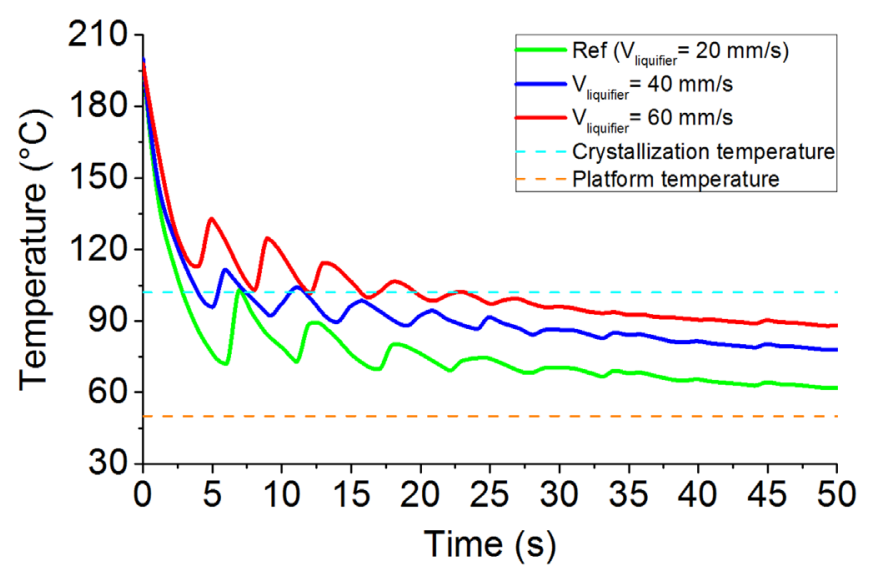

F I G URE 8 Temperature profile $\left( \pm 2^{\circ} \mathrm{C}\right)$ of vertical wall at $(x=5 \mathrm{~mm})$ from the start of deposition at different print speed [Color figure can be viewed at wileyonlinelibrary.com]

\section{3 | Case studies}

This section demonstrates the usefulness of the proposed in situ temperature measurement technique, by studying the effect of the platform temperature and deposition velocity on the heat transfer during cooling.

Figure 7 shows the temperature evolution of three different temperature of the platform, at location distance $5 \mathrm{~mm}$ from the edge. As expected, the lower the platform temperature the faster the cooling. As for the reheating peaks, they have identical onsets, but the magnitude tends to decreases with increasing platform temperature. When the platform temperature is set to $100^{\circ} \mathrm{C}$, the filament being monitored reheats repeatedly above its $T_{\mathrm{c}}$, favoring bonding.

When the deposition velocity increases (Figure 8), the rate of cooling decreases. Also, and as expected, the onset of 
the peaks occurs at different times and their breadth is also altered. Finally, the magnitude of the peaks for the lowest deposition velocity is higher, probably due to the higher difference between the temperatures of adjacent filaments.

\section{5 | CONCLUSIONS}

This work presents a 'localized measurement' setup enabling to record temperature profile of two adjacent filaments (or a sequence of deposition) during the FFF process. The main characteristic of the proposed method is the accurate measurements of polymer material temperature using $80 \mu \mathrm{m}$ thermocouples. It has been shown that the experimental results are in good agreement with the utilized numerical method. It correctly measures the temperature profile of a single filament and filaments embedded in multilayer parts by taking into account the effect of the variant temperature of the environment and thermal contact conductance between adjacent filaments. A parametric study on the effect of the bed temperature and the printing speed indicated the influence on reheating of the previously deposited filament during additional layer deposition.

These results are important for the understanding of filament bonding. The main outcome of this study is to apply the incoming results for prediction of bonding and consequently to optimize the strength of successively deposited layers. Future work will focus on the improvement of the proposed setup to show its capacity in complex geometry. Accordingly, it could help the optimization of bonding quality by correlating the thermal and mechanical characteristic results.

\section{ORCID}

Hamid Reza Vanaei (1) https://orcid.org/0000-0003-1501-

0482

\section{REFERENCES}

[1] O. A. Mohamed, S. H. Masood, J. L. Bhowmik, Adv. Manuf. 2015, 3, 42 .

[2] J. Holmström, J. Partanen, J. Tuomi, M. Walter, J. Manuf. Technol Manage. 2010, 21, 687.

[3] J. F. Rodríguez, J. P. Thomas, J. E. Renaud, J. Mech. Design 2003, 125, 545.

[4] P. Kulkarni, A. Marsan, D. Dutta, Rapid prototyping j. 2000, $6,18$.

[5] S. Saeidlou, Cinétique de Cristallisation, Structure Et Applications Des Stéréocomplexes de PLA, Université de Sherbrooke, Québec, Canada 2014.

[6] E. C. Santos, M. Shiomi, K. Osakada, T. Laoui, Int. J. Mach. Tools Manuf 2006, 46, 1459.

[7] A. Iftikhar, M. Khan, K. Alam, S. H. Imran Jaffery, L. Ali, Y. Ayaz, A. Khan, Mater. Manuf. Processes 2013, 28, 534.

[8] D. Yagnik, IOSR J. Mech. Civil Eng 2014, 5, 62.
[9] P. Chennakesava, Y. S. Narayan, Fused deposition modelinginsights. in Proceedings of the International Conference on Advances in Design and Manufacturing ICAD\&M, Vol. 14, Hyderabad, India 2014, p. 1345.

[10] R. W. Hopper, J. Am. Ceram. Soc. 1984, 67, C262.

[11] N. Rosenzweig, M. Narkis, Polym. Eng. Sci. 1981, 21, 1167.

[12] H. R. Vanaei, K. Raissi, M. Deligant, M. Shirinbayan, J. Fitoussi, S. Khelladi, A. Tcharkhtchi, J Mater Sci 2020, https:// doi.org/10.1007/s10853-020-05057-9

[13] A. D'Amico, A. M. Peterson, Addit. Manuf 2018, 21, 422.

[14] C. Kousiatza, D. Karalekas, Mater. Des. 2016, 97, 400.

[15] J. E. Seppala, K. D. Migler, Addit. manuf. 2016, 12, 71.

[16] E. Ferraris, J. Zhang, B. Van Hooreweder, CIRP Annals 2019, $68,213$.

[17] C. Kousiatza, N. Chatzidai, D. Karalekas, Sensors 2017, $17,456$.

[18] Q. Sun, G. Rizvi, C. Bellehumeur, P. Gu, Rapid Prototyping J. 2008, 14, 72 .

[19] J. Zhang, X. Z. Wang, W. W. Yu, Y. H. Deng, Mater. Des. 2017, 130, 59.

[20] M. Atif Yardimci, S. Güçeri, Rapid Prototyping J. 1996, 2, 26.

[21] C. Bellehumeur, L. Li, Q. Sun, P. Gu, J. Manuf. Processes 2004, 6, 170 .

[22] S. Costa, F. Duarte, J. Covas, Virtual.Phys. Prototyping 2015, $10,35$.

[23] S. Costa, F. Duarte, J. Covas, J. Mater. Process. Technol. 2017, 245, 167.

[24] A. Kallel, I. Koutiri, E. Babaeitorkamani, A. Khavandi, M. Tamizifar, M. Shirinbayan, A. Tcharkhtchi, Int. Polym. Process. 2019, 34, 434.

[25] W. Han, M. A. Jafari, K. Seyed, Rapid Prototyping J. 2003, 9, 212.

[26] H. Vanaei, M. Shirinbayan, M. Deligant, K. Raissi, J. Fitoussi, S. Khelladi, A. Tcharkhtchi, Polym. Eng. Sci. 2020, http://dx. doi.org/10.1002/pen.25419.

[27] S.-H. Ahn, M. Montero, D. Odell, S. Roundy, P. K. Wright, Rapid prototyping j. 2002, 8, 248.

[28] M. Spoerk, F. Arbeiter, H. Cajner, J. Sapkota, C. Holzer, J. Appl. Polym. Sci. 2017, 134, 45401.

[29] A. Lucas, A. Danlos, M. Shirinbayan, V. Motaharinejad, R. Paridaens, K. Benfriha, F. Bakir, A. Tcharkhtchi, Int. J. Adv. Manuf. Technol. 2019, 104, 1183.

[30] S. F. Costa, F. M. Duarte, J. A. Covas, J. Mater. Form. 2008, 1, 703. http://dx.doi.org/10.1007/s12289-008-0312-9

[31] F. Yang, R. Pitchumani, Macromolecules 2002, 35, 3213.

[32] J. F. Rodríguez, J. P. Thomas, J. E. Renaud, Rapid prototyping j. 2001, 7, 148.

[33] A. D. Kraus, A. Aziz, J. Welty, D. Sekulic, Appl. Mech. Rev. 2001, 54, B92.

[34] J. P. Holman, Transferência de Calor. São Paul o, McGraw-Hill do Brasil, São Paulo 1983. 